\title{
Logistics issues of biomass: The storage problem and the multi-biomass supply chain
}

\author{
Athanasios A. Rentizelas*, Athanasios J. Tolis, Ilias P. Tatsiopoulos \\ Department of Mechanical Engineering, Sector of Industrial Management and Operational Research, \\ National Technical University of Athens, 9 Iroon Polytechniou Street, Zografou 15780, Athens, Greece \\ Received 19 November 2007; accepted 7 January 2008
}

\begin{abstract}
Biomass is a renewable energy source with increasing importance. The larger fraction of cost in biomass energy generation originates from the logistics operations. A major issue concerning biomass logistics is its storage, especially when it is characterized by seasonal availability. The biomass energy exploitation literature has rarely investigated the issue of biomass storage. Rather, researchers usually choose arbitrarily the lowest cost storage method available, ignoring the effects this choice may have on the total system efficiency. In this work, the three most frequently used biomass storage methods are analyzed and are applied to a case study to come up with tangible comparative results. Furthermore, the issue of combining multiple biomass supply chains, aiming at reducing the storage space requirements, is introduced. An application of this innovative concept is also performed for the case study examined. The most important results of the case study are that the lowest cost storage method indeed constitutes the system-wide most efficient solution, and that the multi-biomass approach is more advantageous when combined with relatively expensive storage methods. However, low cost biomass storage methods bear increased health, safety and technological risks that should always be taken into account.
\end{abstract}

(C) 2008 Elsevier Ltd. All rights reserved.

Keywords: Logistics; Biomass storage; Multi-biomass; Biomass supply chain; Energy exploitation; Agricultural biomass

\section{Contents}

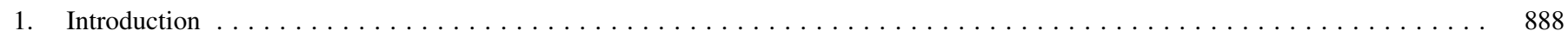

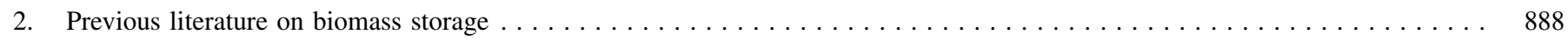

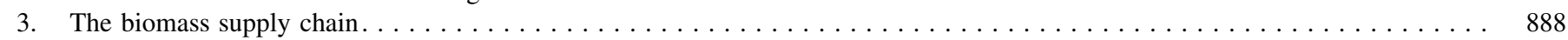

3.1. Typical layout $\ldots \ldots \ldots \ldots \ldots \ldots \ldots \ldots \ldots \ldots$

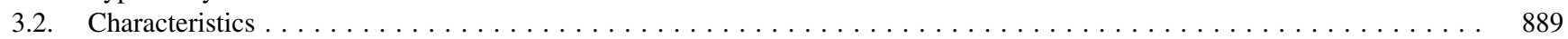

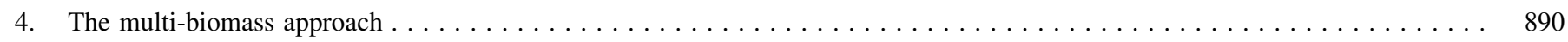

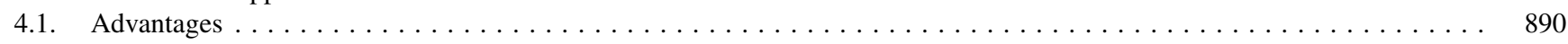

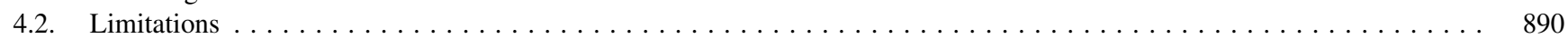

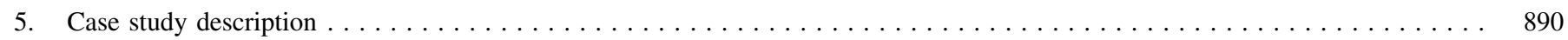

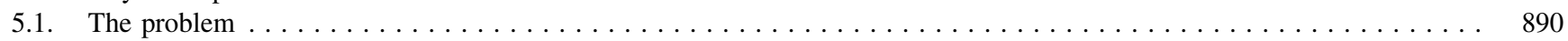

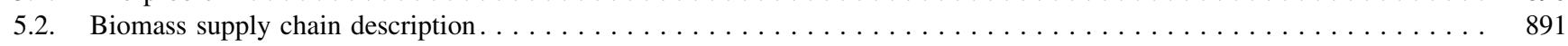

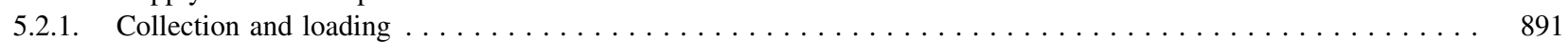

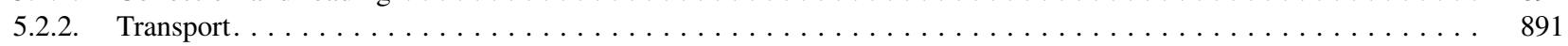

5.2.3. Unloading and storage $\ldots \ldots \ldots \ldots \ldots \ldots \ldots \ldots \ldots \ldots \ldots \ldots \ldots$

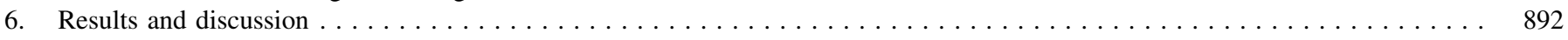

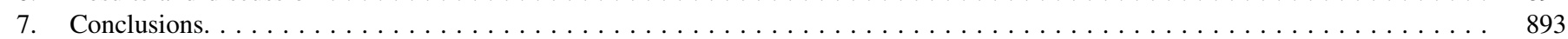

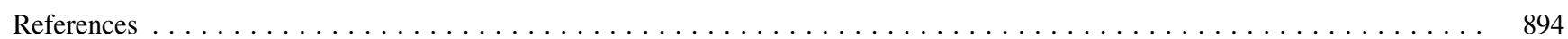

* Corresponding author. Tel.: +30 210 7722383; fax: +30 2107723571.

E-mail address: arent@central.ntua.gr (A.A. Rentizelas). 


\section{Introduction}

Biomass is one of the renewable energy sources on which policy makers are greatly based upon to reduce the greenhouse gas emissions. One of its main advantages is that it is a very versatile energy source, generating not only electricity but also heat and biofuels to be used in the transportation sector. It is also one of the few renewable energy sources that may be stored and can generate energy on-demand. The academic community has also been very interested in the energy exploitation of biomass. Several studies have been performed to forecast the contribution of biomass in the future energy supply, both at a regional and at a global level [1-3]. All of these studies conclude to the fact that biomass usage will be increased significantly in the years to come. Nonetheless, there is no consensus on the maximum level biomass exploitation could achieve.

One of the most important barriers in increased biomass utilization in energy supply is the cost of the respective supply chain and the technology to convert biomass into useful forms of energy. It is therefore natural that many attempts have been made to date to simulate and optimize a specific biomass supply chain on the understanding that significant cost reductions could originate from more efficient logistics operations. Most of the research work performed concerns simulation models of the biomass supply chain, focusing on various aspects of the logistics operations.

The cost of producing short rotation forestry was investigated by using spreadsheet models in ref. [4], focusing mainly on the operations of biomass production, collection and storage. An analytic supply chain modeling for 5 biomass types was performed in ref. [5], concluding that 20-50\% of biomass delivered cost is due to transportation and handling activities. Similarly, very analytical supply chain simulation models for forest [6], cotton [7] and Miscanthus giganteus biomass [8] have been developed. GIS has also been employed in several studies $[9,10]$ to calculate the exact transportation distances for supplying specific amounts of energy crop feedstock across a state, taking into account the spatial variability in their yield.

\section{Previous literature on biomass storage}

The stage of biomass storage is a very critical link on the respective supply chain. In most cases of the relevant research work low cost storage solutions are chosen, without examining the positive effect that more sophisticated (and more costly) solutions may have. Many researchers assume on-field biomass storage [5,8,11]. Both ambient and covered on-field storage has also been examined [12]. The method of on-field storage has the advantage of low cost but on the other hand, biomass material loss is significant and biomass moisture cannot be controlled and reduced to a desired level, thus leading to potential problems in the power plant technological devices. Furthermore, health and safety issues exist, such as the danger of spores and fungus formation [5,13] and self-ignition due to increased moisture. Finally, the farmers may not allow on-farm storage of the biomass for a significant time period, as they may want to prepare the land for the next crop [11].

Several authors consider the use of intermediate storage locations between the fields and the power plant [5,14,15]. For all biomass fuels in which the use of intermediate storage has been modelled, the fuel has to be transported twice by road transport vehicles (first from farm/forest to the intermediate storage facility and then from storage to the power station). This fact will result in a higher delivered cost than a system in which there is only one road transport movement (directly from farm/ forest to power station). Using an intermediate storage stage may add in the region of $10-20 \%$ to the delivered costs, as a result of the additional transportation and handling costs incurred [5].

Finally, the option of settling the storage facility next to the biomass power plant has also been examined in the relevant literature $[15,16]$. On the latter case, an innovative storage layout with biomass drying capability using dumped heat from the power plant was presented. This concept aims at reducing faster the biomass moisture content and prevents material decomposition as well as fungus and spores formation. Using storage facilities attached to the power plant is the only viable case of accelerating the drying process of the biomass, as dumped heat may be used without need for extra energy consumption.

It is obvious that the biomass supply chain literature has not paid to the issue of biomass storage the attention it deserves. In most cases the lowest possible cost solution is adopted, without examining the effect this solution may have on the total system cost. This work aims at comparing three biomass storage solutions found in the literature, in terms of total system cost. The concept of multi-biomass is also adopted in its simplest form: two locally available biomass types are considered, as this concept may lead to significant system cost reduction [14]. The analysis is performed by examining a case study, in order to come up with some tangible results.

\section{The biomass supply chain}

\subsection{Typical layout}

A typical biomass supply chain is comprised of several discrete processes. These processes may include ground preparation and planting, cultivation, harvesting, handling, storage, in-field/forest transportation, road transportation and utilization of the fuel at the power station.

Considering the typical locations of biomass fuel sources (i.e. in farms or forests) the transport infrastructure is usually such that road transport will be the only potential mode for collection and transportation of the fuel. Other factors that favour the use of road transport include the relatively short distances over which the fuel is transported and the greater flexibility that road transport can offer in comparison with other modes. Other transportation means, such as ship or train may be considered when long distance biomass transport is examined [17]. However, this is not the case in this work, where emphasis is placed on locally existing biomass types. 
The activities required to supply biomass from its production point to a power station [5] are the following:

- Harvesting/collection of the biomass in the field/forest.

- In-field/forest handling and transport to move the biomass to a point where road transport vehicles can be used.

- Storage. Many types of biomass are characterized by seasonal availability, as they are harvested at a specific time of the year but are required at the power station on a year-round basis; it is therefore necessary to store them. The storage point can be located in the farm/forest, at the power station or at an intermediate site.

- Loading and unloading of the road transportation vehicles. Once the biomass has been moved to the roadside it will need to be loaded to road transportation vehicles for conveyance to the power station. The biomass will need to be unloaded from the vehicles at the power station.

- Transport by road transportation vehicles. There are varying opinions in the literature on whether it is more economical to use heavy goods vehicles [5,8] or agricultural/forestry equipment [15] for biomass transport to the power station. Ultimately, it appears to be a matter of the average transport distance, biomass density, the carrying capacity and travelling speed of the respective vehicles, as well as their availability.

- Processing biomass to improve its handling efficiency and the quantity that can be transported. This may involve increasing the bulk density of biomass (e.g. processing forest fuel or coppice stems into wood chips) or unitising the biomass (e.g. processing straw or Miscanthus in the swath into bales). Processing can occur at any stage in the supply chain but will often precede road transport and is generally cheaper when integrated with the harvesting.

In the present work, a relatively simple but typical biomass supply chain design has been adopted. The requirement of developing a generic supply chain model for examining several biomass types and also the multi-biomass approach, including any combination of biomass types, led to the supply chain design that is presented in Fig. 1.

\subsection{Characteristics}

The biomass supply chain presents several distinctive characteristics that diversify it from a typical supply chain. First of all, agricultural biomass types are usually characterized by seasonal availability [18]. The period when these biomass types are available is very limited and is determined by the crop harvesting period, the weather conditions and the need to replant the fields. Since most of the biomass-to-energy applications to date concern single biomass use, there is a need of storing very large amounts of biomass for a significant time period, if year-round operation of the power plant is desired. The limited time frame for collecting a large amount of biomass leads also to significant seasonal need of resources, both equipment and workforce. This seasonal demand may increase the cost of obtaining these resources, while leading to suboptimal utilization of resources, particularly of the storage space. The problems introduced by the seasonality of biomass availability may be avoided, if a biomass that is available yearround is used, which is very rare in practice. The multi-biomass approach may smooth significantly these problems and this is why this approach is examined here.

Another characteristic of the biomass supply chain is that it has to deal with low-density materials. As a result, there is increased need for transportation and handling equipment, as well as storage space. This problem is enhanced by the low heating value, which is partly due to the increased moisture of most agricultural biomass types. The low density of biomass increases further the cost of collection, handling, transport and storage stages of the supply chain [5].

Finally, several biomass types require customized collection and handling equipment, leading to a complicated structure of the supply chain. For example, there are different requirements on handling and transportation equipment and storage space configuration if biomass is procured in the forms of sticks or chips [5]. Therefore, the form in which the biomass will be procured often determines the investment and operational costs of the respective bioenergy exploitation system, as it affects the requirements and design of the biomass supply chain.

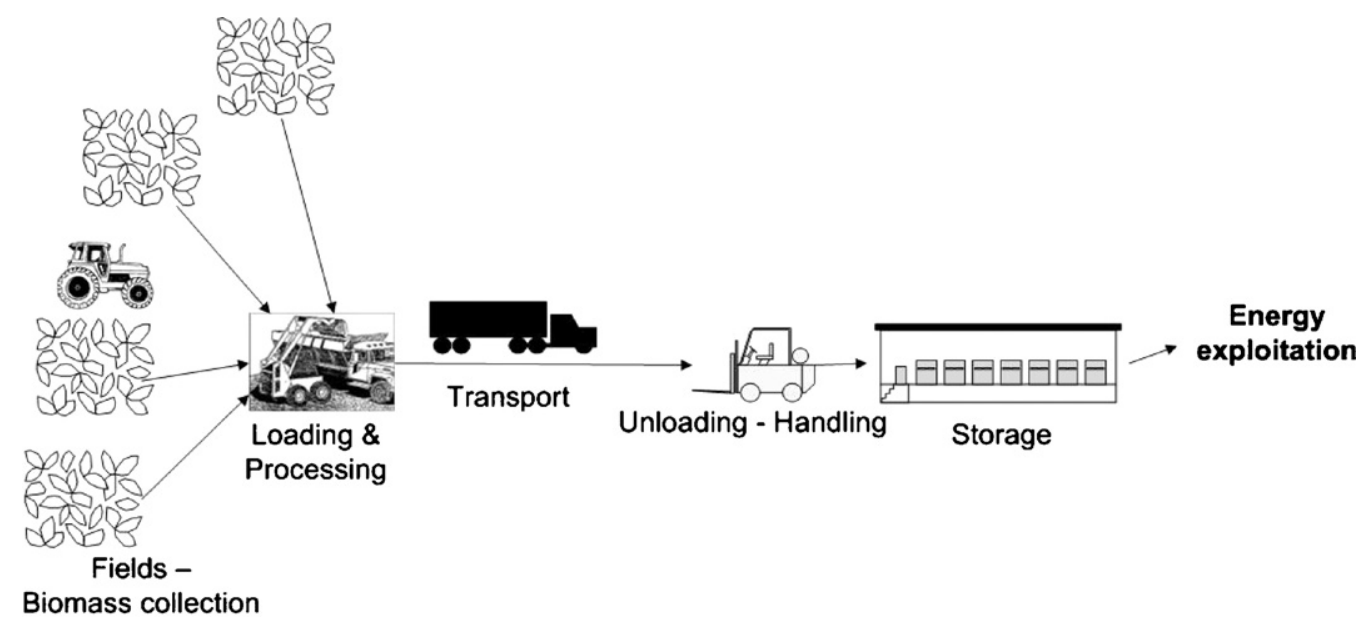

Fig. 1. Generic biomass supply chain design. 
All of the abovementioned factors lead to increased supply chain cost and require significant attention in designing a biomass power plant, in order to reduce their negative impact to the financial yield of the entire system. The multi-biomass approach aims at reducing the impact of these factors.

\section{The multi-biomass approach}

The concept of multi-biomass utilization has been rarely dealt with by researchers up to now, despite the advantages that such an approach is expected to have. For example, in ref. [17] the need for widening the operational window of biomass logistics is acknowledged, e.g. by combining multiple biomass chains, to minimize the share of capital costs.

The research that has been performed on the multi-biomass concept has been very limited to date. For example, the simultaneous use of straw and reed canary grass has been investigated [14]. The conclusion the researchers reached was that the specific combination led to a total system cost reduction of about $15-20 \%$ compared to a single-biomass case, despite the increased production cost of reed canary grass compared to straw. Another interesting work examined the case of utilizing six biomass sources, including municipal solid waste [16]. In this research, the criterion for the technical capability of using the biomass mix was the Lower Heating Value of the mix. The cost of producing energy using all the available biomass types in a certain region was determined [19]. Finally, a case study for utilizing multiple forest biomass types for local district heating applications, using GIS for logistics modeling was presented [20].

\subsection{Advantages}

The advantages that one may expect from using multiple biomass sources lie mainly on the total system cost reduction. Significant savings can be realized in the stage of storage, as the inflow of biomass throughout the year may be smoother and the storage space required may be reduced. Furthermore, additional cost savings could be expected from smoother resource requirements at the biomass supply chain, both equipment and labor. The example of ref. [14], where a $15-20 \%$ cost reduction was obtained simply by using two biomass sources instead of one is indicative of the cost reduction potential of the multi-biomass approach.

\subsection{Limitations}

A major reason for the limited research on the multi-biomass approach up to now is mainly the difficulties and limitations introduced by this approach. The logistics can become quite complex, especially when a variety of biomass streams are involved. Organizational aspects, variations in availability, storage and backup fuel, especially in winter months, are issues that require more detailed study, according to ref. [21].

One of the main technical challenges of the multi-biomass approach is the ability of the available energy conversion technology to use a fuel mix comprised of several biomass types with varying fuel characteristics, or a fuel that will vary its characteristics according to the season of the year. There is no absolute solution to this issue. Several energy conversion technologies are tolerant to the variability of fuel characteristics, whereas others are extremely sensitive even to small fuel characteristics variations (e.g. pyrolysis). However, in ref. [21] the existence of technologies capable of coping with simultaneous use of biomass types with varying fuel properties or contamination level is acknowledged. Furthermore, there exist several families of biomass types that have very similar characteristics and fuel properties (e.g. woody biomass types, several cereal biomass types, etc.). In this work, it is assumed that a suitable technology will be considered to use the fuel mix that may result from the locally available biomass sources of the case study region.

Another issue stemming from the multi-biomass approach concerns the equipment for handling and processing the several biomass sources. Most biomass types can be processed into numerous forms, each one potentially requiring different equipment for handling, loading, unloading, transport and fuel feeding. It is essential for the multi-biomass approach that all the potential biomass sources may be processed in a form that will allow the use of only one type of handling and feeding equipment or that will require small, inexpensive and easily made modifications and customizations. Otherwise the advantage of using multiple biomass types on the capital cost reduction of the equipment may be wiped out. Therefore, the multi-biomass approach requires that the biomass types examined may have a similar form that will allow using the same equipment for all of them.

\section{Case study description}

\subsection{The problem}

The model developed is implemented for the case study of a municipality of the prefecture of Thessaly, Greece. Thessaly is one of the most appropriate cases for implementing the model, since it is the largest plain in Greece, in which a large number of different crops exist. The availability of many biomass types is a prerequisite for the examination of the impact of the multibiomass approach.

The heat consumer is considered to be the local community of Farkadon. The reasons for choosing this specific community is its size (about 2000 inhabitants), which makes it ideal for the typical biomass energy applications, and its geographical position. The co-generation power plant is centralized, and is considered to be an independent producer, as all the electricity produced is supplied to the national grid. The heat generated is used mainly for domestic and public sector applications, for space heating or space cooling, by using absorption chillers. Therefore, a tri-generation application is considered. The ultimate target is to build a biomass-to-energy exploitation unit that will operate on heat-match mode.

The results provided in this work concern the biomass supply chain. However, these results have been obtained by applying the global optimization concept on a system-wide 
base. Therefore, for each case examined the whole bioenergy exploitation system is optimized. The system comprises of the biomass supply chain (upstream), the energy exploitation unit (power plant) and the energy products distribution supply chain (downstream), namely electricity, heat and cooling.

The cases examined in this work refer to the following biomass types:

1. Cotton stalks.

2. Almond tree prunings.

The optimum biomass mix has been determined for each scenario examined. These biomass types are among the ones locally prevailing in the region around the case study municipality. In order to perform the case study, raw statistical data for biomass availability at the case study region has been obtained and has been processed with GIS software to attach the appropriate geographical information.

\subsection{Biomass supply chain description}

In this paragraph, the supply chain design adopted for the case study examined is presented. The biomass supply chain may be analyzed to the discrete stages of collection, loading, transport, unloading, handling and storage. These stages are described in more detail.

\subsubsection{Collection and loading}

The model used has the ability of investigating a multibiomass supply chain. The complexity introduced by the many potential collection methods and forms for each biomass type is enormous. For this reason, only one collection method and one form for each biomass type has been considered in the case study. The biomass types will be converted either to chips or chopped form. The characteristics of each biomass type are introduced parametrically in the model. The input data used for biomass are displayed in Table 1.

The biomass types considered do not have significant alternative use and specific market price currently in Greece. Actually, farmers often have to pay to dispose this type of agricultural residues. Therefore, it has been assumed that they

Table 1

Characteristics of two prevailing biomass types in the case study region

\begin{tabular}{|c|c|c|}
\hline & $\begin{array}{l}\text { Cotton } \\
\text { stalks }\end{array}$ & $\begin{array}{l}\text { Almond tree } \\
\text { prunings }\end{array}$ \\
\hline Residue yield (t/ha) ${ }^{a}$ & 5.47 & 6.21 \\
\hline Residue availability factor $(\%)^{\mathrm{a}, \mathrm{b}}$ & 70 & 90 \\
\hline Biomass remaining for energy exploitation (t/ha) & 3.83 & 5.59 \\
\hline Moisture wet $(\%)^{\mathrm{a}}$ & 30 & 40 \\
\hline HHV (MJ/dry kg) ${ }^{\mathrm{a}, \mathrm{b}}$ & 18.1 & 18.4 \\
\hline Density $\left(\mathrm{kg} / \mathrm{m}^{3}\right)$ & 200 & 300 \\
\hline Availability of biomass & $\begin{array}{l}\text { October- } \\
\text { November }\end{array}$ & $\begin{array}{l}\text { December- } \\
\text { February }\end{array}$ \\
\hline Purchasing price (€/t wet $)^{\mathrm{c}}$ & 20 & 30 \\
\hline
\end{tabular}

\footnotetext{
a Source: [19].

b Source: [16].

c Biomass purchasing price includes also loading costs.
}

may be available at a very low price. The prices shown in Table 1 include also the loading cost to the transportation vehicles.

\subsubsection{Transport}

There are two possible means for performing the biomass transport:

1. Using trucks from a 3PL (third party logistics) company.

2. Using the farmers' equipment (tractors and platforms).

In the current work, it has been assumed that chartered trucks will be used. The reason is that the extended usage period, resulting from adopting the multi-biomass approach, will probably conflict with the availability of farmer's equipment, since it might be needed for other agricultural processes. The data used for the transportation stage of the supply chain are presented in Table 2. Technical data for trucks have been adopted from ref. [8].

Transport cost is a function of the travel distance and the travel time. Travel distance affects mainly the fuel consumption of transportation vehicles, whereas travelling time affects mainly the proportion of depreciation, insurance, maintenance and labour allocated to the specific trip. Travelling time includes the round-trip time, since no return load is available, as well as the loading and unloading waiting time. Each biomass type is assumed to be collected and transported at a constant rate during the whole availability period of the specific type. Due to the low density of all biomass types, the capacity of the transportation vehicles will ultimately be limited by the volume and not by the weight of the cargo. The travelling distance has been calculated from the Euclidean distance multiplied by a tortuosity factor equal to $\sqrt{2}$, to account for the windings of the rural road infrastructure.

\subsubsection{Unloading and storage}

Biomass is transported from the fields to the storage facility, which is assumed to be attached to the biomass CHP plant. The first type of storage assumed is closed warehouse with biomass drying capability, by hot air injection (scenario WD). Hot air is generated by dumped heat of the CHP plant and is supplied from the warehouse floor through appropriate canals and grids. The biomass storage using hot air helps to avoid quality degradation of the biomass due to infections, fermentation and

Table 2

Transportation vehicles characteristics

Max biomass purchasing distance $(\mathrm{km})$ 40

Weight capacity of truck $(\mathrm{kg})$ 25,000

Volume capacity of truck $\left(\mathrm{m}^{3}\right)$ 100

Mean speed of empty vehicle $(\mathrm{km} / \mathrm{h})$

Mean speed of loaded vehicle $(\mathrm{km} / \mathrm{h})$

Mean truck fuel consumption $(1 / \mathrm{km})$

Purchasing cost of truck (€)

Truck insurance and maintenance cost $(€ / \mathrm{yr})$

Service life of truck (yr)

Drivers' shift duration (h)

Drivers' hourly pay rate (€) 
material loss, while simultaneously increasing the energy content of the biofuel by reducing its moisture. For this reason, the material loss of biomass during storage has been assumed negligible, according also to the suggestions of refs. [12,15].

The second biomass storage scenario concerns a covered storage facility of a pole-frame structure having a metal roof without any infrastructure for biomass drying (scenario CNDCovered No Drying storage option), according to ref. [12]. This type of storage does not prevent biomass material loss, and therefore, a $0.5 \%$ material loss/month rate has been assumed, similar to ref. [22].

The third biomass storage scenario concerns ambient storage of biomass, covered only with a plastic film (scenario AS-Ambient Storage), similar to refs. [8,12]. This scenario will have the highest material loss rate, which is assumed to be $1 \%$ material loss/month, according to ref. [12].

An important issue has been the determination of the safety inventory level. For the specific case study it has been assumed that there should always be biomass inventory in the storage facility equal to the one required for 20-day full load operation of the biomass CHP plant. It is assumed that a warehouse with specifications similar to the WD scenario will be constructed also for the CND and the AS scenarios, but its size will be restricted to accommodate only the safety inventory. This requirement aims at securing the reliability of the system towards the end customers, namely the customers of district energy, while at the same time ensuring that biomass will have dried to a significant extent before it is used, in order to avoid potential technical problems incurred due to high biofuel moisture. The rest of the inventory will be stored in the lower cost constructions described for each scenario.

It should be mentioned here that the biomass quality degradation issue related to the CND and especially the AS way of storage was not modeled. Furthermore, the two low-cost scenarios involve another supply chain link, which concerns intermediate biomass movement from the covered storage facility or the ambient storage space to the warehouse where drying takes place.

The size of the storage space required is determined by the maximum yearly biomass inventory level. Therefore, it is necessary to minimize the maximum yearly inventory level in order to reduce the storage cost. The approach of multi-biomass aims at significantly reducing this cost.

Unloading is performed using wheel loaders. Transportation vehicles are assumed to have unloading capabilities and they will unload biomass at the yard of the biomass storage facility. Loaders are used to transfer this biomass into the appropriate storage space. Loaders of the same type are used to handle the biomass inventory and to feed a conveyor belt that supplies the CHP plant with biomass from the storage facility.

It is also necessary to introduce a stage of biomass processing, in order to give biomass characteristics (size, etc.) that will allow its use in the gasifier. This stage would ideally take place after storage and before energy exploitation, in order to allow storage in the optimum for each biomass type form.

The cost of the constructions for the total lifetime of the system has been converted into present values. The main
Table 3

Main characteristics of WD, CND and AS scenarios

\begin{tabular}{llcr}
\hline & \multicolumn{2}{l}{ Scenario } & \\
\cline { 2 - 4 } & WD & CND & AS \\
\hline Material loss (\% per month) & Negligible & $0.5 \%$ & $1 \%$ \\
Storage investment cost $\left(€ / \mathrm{m}^{2} \mathrm{PV}\right)$ & 222 & 110 & 22 \\
Storage O\&M costs $(\%$ investment/yr) & 5 & 4 & 4 \\
Inventory maximum height $(\mathrm{m})$ & 6 & 6 & 3 \\
\hline
\end{tabular}

differences between the three scenarios can be seen in Table 3 . It is interesting to investigate whether the lower storage cost of the CND and AS scenarios will offset the increased need for biomass to replace the material losses.

\section{Results and discussion}

The optimal biomass quantities for the scenarios examined are presented in Table 4. The CND scenario's optimal solution indicates a shift of the biomass types used towards increased use of cotton stalks and reduced amounts of almond tree prunings. The AS scenario's optimum solution suggests the use of only cotton stalks biomass, which is the cheapest biomass type considered in this study. Therefore, the AS scenario ends up being a single-biomass scenario, despite the fact that two biomass types were initially considered. The reason for this shift will be analyzed later on.

Furthermore, one may note that the amount of biomass collected at the AS scenario is quite larger than the one for the WD scenario. The reason for increased biomass requirement is mainly the increased material losses of the AS scenario. Therefore, more biomass will have to be collected in order to have the same final energy content input at the power plant.

The basic allocation of the biomass logistics cost in Present Values for the three scenarios is presented in Table 5.

The total cost of the logistics function is significantly reduced for the CND scenario, at about $9.1 \%$ compared to the base-case WD scenario. What is interesting is that this reduction is mostly due to the significant reduction of the storage stage cost by about $14.4 \%$, while transportation and purchasing and loading costs are slightly reduced, by 3.8 and $1.8 \%$, respectively (Table 6). The same observations can be made for the AS scenario, where the cost reduction is even stronger. The storage stage cost is reduced by $29.8 \%$ compared to the WD scenario, while transportation and the biomass purchasing costs are reduced by 12.5 and $9.1 \%$, respectively. An explanation for this behaviour is that the storage cost reduction of scenarios CND and AS exceeds by far the extra cost incurred by biomass material losses and by increased

Table 4

Optimal biomass quantities

\begin{tabular}{llrr}
\hline Biomass type & \multicolumn{2}{l}{ Scenario } & \\
\cline { 2 - 4 } & WD & CND & AS \\
\hline Cotton stalks (t/yr) & 9456 & 10,197 & 13,799 \\
Almond tree prunings (t/yr) & 3808 & 3,141 & - \\
\hline
\end{tabular}


Table 5

Optimal logistics cost allocation

\begin{tabular}{lrrr}
\hline Logistics cost & \multicolumn{2}{l}{ Scenario } & \\
\cline { 2 - 4 } & WD & CND & AS \\
\hline Purchasing and loading (million $€ \mathrm{PV}$ ) & 3.72 & 3.65 & 3.38 \\
Transportation (million $€ \mathrm{PV}$ ) & 0.32 & 0.31 & 0.28 \\
Storage \& Handling (million $€ \mathrm{PV})$ & 5.35 & 4.58 & 3.76 \\
Total logistics cost (million $€ \mathrm{PV})$ & 9.39 & 8.54 & 7.42 \\
\% of WD scenario (total) & $100 \%$ & $90.9 \%$ & $79.0 \%$
\end{tabular}

Table 6

Logistics cost allocation compared to WD scenario

\begin{tabular}{llll}
\hline & WD & CND & AS \\
\hline Purchasing and loading & $100.0 \%$ & $98.2 \%$ & $90.9 \%$ \\
Transportation & $100.0 \%$ & $96.2 \%$ & $87.5 \%$ \\
Storage and handling & $100.0 \%$ & $85.6 \%$ & $70.2 \%$ \\
\hline
\end{tabular}

handling cost. In total, the logistics operations of the CND scenario cost $9.1 \%$ less compared to the WD scenario and the AS scenario is by far the most economic, as the related cost is $21 \%$ less than the WD scenario. The cost of each stage of the biomass supply chain is presented graphically in absolute values in Fig. 2.

It is also evident that the need for reducing the storage space required is stronger for the cases where expensive biomass storage options are considered. The increase of the average inventory level for the CND and even more for the AS scenarios is evident at Fig. 3. This figure shows that using more expensive biomass types to achieve storage space requirements reduction is an efficient solution when expensive storage options are applied. In any case though, the storage space required for the year-round operation of the power plant is very large, ranging from $6667 \mathrm{~m}^{2}$ for the WD scenario, to almost $23,000 \mathrm{~m}^{2}$ for the AS scenario. From Fig. 3, it is obvious that scenario WD utilizes the almond pruning biomass to "trim" the inventory peak that appears during the winter months for the lower cost storage scenarios. Actually, the incoming amount of almond tree prunings biomass during the months November to February

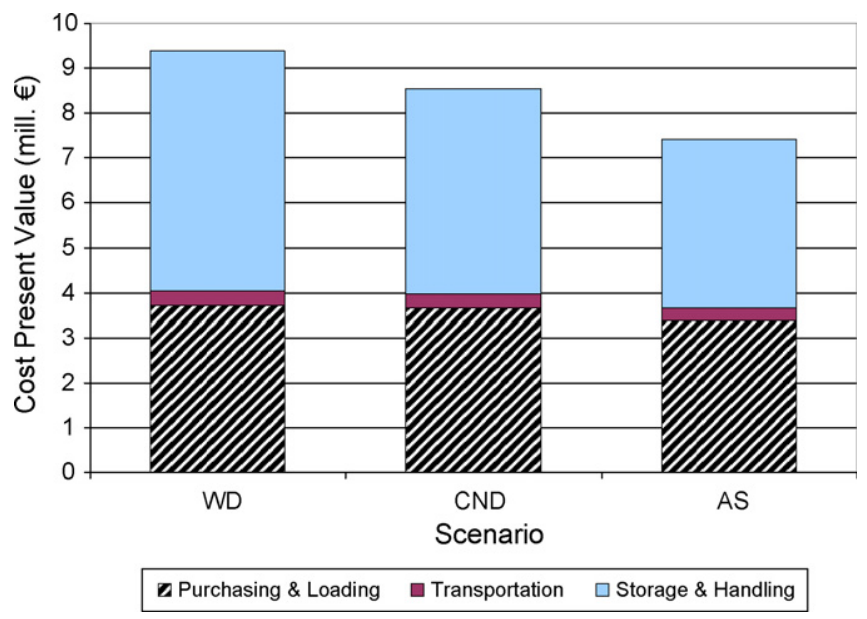

Fig. 2. Biomass supply chain cost analysis.

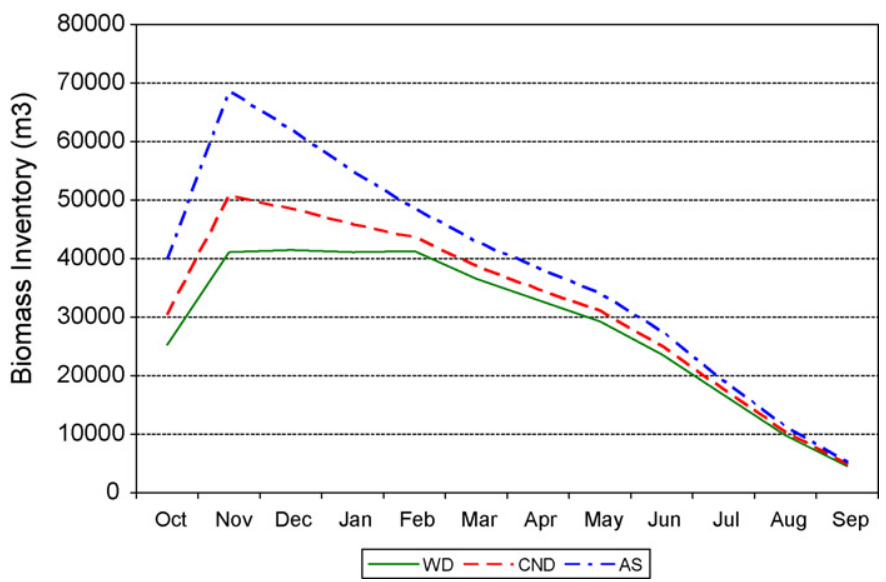

Fig. 3. Biomass inventory profile.

Table 7

Logistics costs allocation to its major operations

\begin{tabular}{lcrr}
\hline & WD & \multicolumn{1}{c}{ CND } & \multicolumn{1}{c}{ AS } \\
\hline Purchasing and loading & $39.6 \%$ & $42.8 \%$ & $45.6 \%$ \\
Transportation & $3.4 \%$ & $3.6 \%$ & $3.8 \%$ \\
Storage and handling & $57.0 \%$ & $53.6 \%$ & $50.6 \%$ \\
Total & $100 \%$ & $100 \%$ & $100 \%$ \\
\hline
\end{tabular}

is roughly equal to the biomass demand for energy generation, thus leading to an almost level inventory profile during winter. The difference of the three graphs concerning the months March to September is a result of the material losses characterising each scenario, as these is no biomass entering the storage facility during this period.

The contribution of each logistics stage to the total logistics cost of each scenario is presented in Table 7. Biomass purchasing and loading has the larger contribution for the AS scenario compared to the other scenarios. On the other hand, the contribution of storage and handling of biomass is higher for the WD base-case scenario. The contribution of the transportation stage is also slightly increased at the AS scenario, when compared to the WD one. These findings are primarily a result of the significantly increased storage cost in absolute terms for the WD scenario.

\section{Conclusions}

As a conclusion, the application of a cheaper storage solution leads to significant cost reduction at the storage and handling stage of the biomass supply chain, which results in considerable cost savings for the whole biomass logistics function. This reduction exceeds by far the extra cost imposed by biomass material losses and increased handling cost characterising the simpler storage solutions applied. However, side-effects of applying cheaper storage solutions without biomass drying, such as heating value reduction of the biomass, health and fire risks, etc., should be further investigated. Consequently, the need for a detailed logistical analysis for each potential application of a bioenergy exploitation system, 
taking into account the specific details of the locally prevailing biomass types, is pinpointed.

Based on the case study results it can be inferred that when simple and cheap storage solutions can be used, choosing the cheapest biomass type available appears to be the wisest choice. On the other hand, multi-agricultural biomass approach appears to be attractive for systems where expensive storage solutions are used, in order to reduce the storage space required.

In real world conditions, the positive effect of biomass drying during storage depends strongly on the moisture level of the incoming biomass. If the biomass types used are brought for storage with small moisture content (e.g. 15-20\%), then the effect of biomass drying during storage is not so significant, and therefore storage without drying can be safely used. However, agricultural residue biomass types are usually characterized by high moisture content when collected (usually 40-50\%) and there is no time available to let them dry in the field, as the farmers need, in most cases, to prepare the land for the next crop and biomass will decay if left in the field. If biomass is stored with high moisture content without drying, then the problems of quality degradation, material loss, fire danger or even formation of microbes dangerous to human health may become critical.

\section{References}

[1] Berndes G, Hoogwijk M, Van Den Broek R. The contribution of biomass in the future global energy supply: a review of 17 studies. Biomass Bioenergy 2003;25:1-28.

[2] Yamamoto H, Fujino J, Yamaji K. Evaluation of bioenergy potential with a multi-regional global-land-use-and-energy model. Biomass Bioenergy 2001;21:185-203.

[3] Jager-Waldau A, Ossenbrink H. Progress of electricity from biomass, wind and photovoltaics in the European Union. Renew Sustain Energy Rev 2004;8:157-82.

[4] Mitchell CP, Stevens EA, Watters MP. Short-rotation forestry-operations, productivity and costs based on experience gained in the UK. Forest Ecol Manage 1999;121:123-36.

[5] Allen J, Browne M, Hunter A, Boyd J, Palmer H. Logistics management and costs of biomass fuel supply. Int J Phys Distrib Logistics Manage 1998;28:463-77.

[6] Gallis CT. Activity oriented stochastic computer simulation of forest biomass logistics in Greece. Biomass Bioenergy 1996;10:377-82.

[7] Gemtos TA, Tsiricoglou T. Harvesting of cotton residue for energy production. Biomass Bioenergy 1999;16:51-9.

[8] Huisman W, Venturi P, Molenaar J. Costs of supply chains of Miscanthus giganteus. Ind Crops Prod 1997;6:353-66.

[9] Graham RL, English BC, Noon CE. A Geographic Information Systembased modeling system for evaluating the cost of delivered energy crop feedstock. Biomass Bioenergy 2000;18:309-29.

[10] Graham RL, Liu W, Downing M, Noon CE, Daly M, Moore A. The effect of location and facility demand on the marginal cost of delivered wood chips from energy crops: a case study of the state of Tennessee. Biomass Bioenergy 1997;13:117-23.

[11] Sokhansanj S, Kumar A, Turhollow AF. Development and implementation of integrated biomass supply analysis and logistics model (IBSAL). Biomass Bioenergy 2006;30:838-47.

[12] Cundiff JS, Dias N, Sherali HD. A linear programming approach for designing a herbaceous biomass delivery system. Bioresour Technol 1997;59:47-55.
[13] Nilsson D. SHAM — a simulation model for designing straw fuel delivery systems. Part 1: model description. Biomass Bioenergy 1999;16:25-38.

[14] Nilsson D, Hansson PA. Influence of various machinery combinations, fuel proportions and storage capacities on costs for co-handling of straw and reed canary grass to district heating plants. Biomass Bioenergy 2001;20:247-60.

[15] Tatsiopoulos IP, Tolis AJ. Economic aspects of the cotton-stalk biomass logistics and comparison of supply chain methods. Biomass Bioenergy 2003;24:199-214.

[16] Papadopoulos DP, Katsigiannis PA. Biomass energy surveying and techno-economic assessment of suitable CHP system installations. Biomass Bioenergy 2002;22:105-24.

[17] Hamelinck CN, Suurs RAA, Faaij APC. Large scale and long distance biomass supply chains: logistics, costs, energy consumption, emission balances. In: 2nd World Conference on Biomass for Energy; 2004.

[18] Skoulou V, Zabaniotou A. Investigation of agricultural and animal wastes in Greece and their allocation to potential application for energy production. Renew Sustain Energy Rev 2007;11:1698-719.

[19] Voivontas D, Assimacopoulos D, Koukios EG. Assessment of biomass potential for power production: a GIS based method. Biomass Bioenergy 2001;20:101-12.

[20] Freppaz D, Minciardi R, Robba M, Rovatti M, Sacile R, Taramasso A. Optimizing forest biomass exploitation for energy supply at a regional level. Biomass Bioenergy 2004;26:15-25.

[21] Faaij A, Van Ree R, Waldheim L, Olsson E, Oudhuis A, Van Wijk A, Daey-Ouwens C, Turkenburg W. Gasification of biomass wastes and residues for electricity production. Biomass Bioenergy 1997;12:387-407.

[22] Fischer T, Gaderer M. COBER Deliverables D24 \& D25 - Task 2.3: Power Plant Processes \& Task 2.4. Energy Exploitation. BZAE.AES; 1999.

Athanasios A. Rentizelas holds a mechanical engineering degree from the National Technical University of Athens (NTUA), an MSc in operations management with distinction from UMIST, Manchester, UK and a $\mathrm{PhD}$ on supply chain optimization focused on biomass from NTUA. He is currently a research engineer in the Industrial Management \& Operational Research Sector of NTUA Mechanical Engineering School. His research interests and expertise lie in the areas of supply chain management, logistics, renewable energy sources, investment analysis, optimization and quality management. He has been awarded various academic awards for his exceptional performance during his studies, as well as scholarships for postgraduate studies.

Athanasios J. Tolis is a research engineer and has a degree in mechanical engineering from NTUA and a $\mathrm{PhD}$ on reverse logistics and investment optimization also from NTUA. His main areas of interest are related with economic aspects of renewable energy based power plants, energy economics, investment analysis, industrial forecasting and operational research. He has many years of academic experience since he contributes to the educational activities of the Sector of Industrial Management and Operational Research of the Mechanical Engineering School of NTUA (SIMOR/NTUA).

Ilias P. Tatsiopoulos is a professor in operations management and logistics at the Industrial Management and OR Section of the National Technical University of Athens (NTUA). He has been active for several years as a professional production engineer in both industrial and consulting firms and he served as a lecturer in management information systems at the Economic University of Athens. He studied mechanical and industrial engineering at NTUA (1978) and followed post-graduate studies at the TH Aachen (Germany) and the University of Lancaster (UK) under a NATO grant. He holds a PhD (1983) in operational research from the University of Lancaster. He is a member of the Senate of NTUA, Chairman of the Greek Institute for Production \& Operations Management and member of the board of the Hellenic Management Association (HMA). 